\title{
The Prevalence of Computer Related Musculoskeletal Disorders Among Bankers of Dhaka City
}

\author{
Md Ruhul Amin ${ }^{1 *}$ \\ Sarder Mahmud Hossain ${ }^{2}$ \\ Sumaiya Zabin Eusufzai ${ }^{2}$ \\ Sunam Kumar Barua ${ }^{3}$ \\ Nafii Bin Jamayet ${ }^{4}$
}

'Department of Physiotherapy SAIC Group of Medical Institutions Dhaka, Bangladesh.

${ }^{2}$ Department of Public Health Northern University, Bangladesh.

${ }^{3}$ Department of Physical Medicine Dhaka Medical College, Bangladesh.

${ }^{4}$ Prosthodontic Unit

University Sains Malaysia, Malaysia.

\section{${ }^{*}$ Correspondence to:}

Dr. Md Ruhul Amin

Assistant Professor and Course Coordinator Department of Physiotherapy

SAIC Group of Medical Institutions

Mirpur-6, Dhaka, Bangladesh.

Mobile: +88 01710898500

E-mail: ruhul31physio@yahoo.com

www.banglajol.info/index.php/CMOSHMCJ
Introduction: Bangladesh is a developing country and the industrialization process is also getting momentum. Due to rapid industrialization and mechanization, use every day more people are coming in contact with the information technology, consequently computer use which may enhance sufferings of people by causing musculoskeletal disorders. Objective: to find out among bankers (a) the prevalence of musculoskeletal disorder and (b) the association between musculoskeletal pain and computer use. Methods: This descriptive type of cross sectional study was conducted to see the pattern of musculoskeletal disorders among the computer users in three selected banks of Dhaka city with a sample of 400. Results: More than half of the respondents $(59.8 \%)$ were married, more than two-third $(69.2 \%)$ was male. Majority of the respondents $(58.25 \%$ and $33.0 \%$ ) belonged to the level of education was graduate and post graduate. Statistically significant association found between duration of computer used in years and severity of pain. (P-Value was 0.019). Conclusion: A high proportion of Bangladeshi computer users among bankers reported musculoskeletal disorder at some body site in their occupational lives with the neck and back being injured most often. Education program on prevention and coping strategies for musculoskeletal disorders are recommended for computer users in order to reduce the rate of occupational hazards.

Key words : Bangladesh; Computer users; Musculoskeletal disorder; Pain.

\section{INTRODUCTION}

Musculoskeletal Disorders are a significant burden on sufferers, employers. The term musculoskeletal disorders enclose a gamut of inflammatory and degenerative conditions that affects the muscles, tendons, ligaments, joints, peripheral nerves, and supporting blood vessels with consequent ache, pain or discomfort ${ }^{1}$. Musculoskeletal disorders are the most common type of work-related health problem in the modern society. In addition the impact on patients themselves, the disorders also form a huge economic burden due to costs for sick leave and health care. Musculoskeletal disorder affects people all over the world. Musculoskeletal disorder is very much related to computer keyboard usage. With proliferation of computer systems in the developing nations, the associated musculoskeletal pain is yet to be investigated ${ }^{2}$. An extensive review of the literature on the association between keyboard usage and prevalence of musculoskeletal disorder showed that the prevalence of keyboardrelated musculoskeletal disorder among computer users is relatively high ${ }^{3}$. Young adult groups are commonly use computers and Internet this day. A study among computer users in a Nigerian University community found that, the most common areas of complaints are the back, neck, eyes and wrist ${ }^{4}$. A study of 'Ergonomics in Back pain' performed in Netherlands in the year of 2003 found that poor awkward postures cause fatigue, strain and eventually pain as well as structural deformation of the body, muscular contractures, pain in the back and legs, decreased lung capacity, poor circulation, intravascular pressure, kinks in the bowel and many irregularities in the body ${ }^{5}$.

Study conducted in Kuwait among computer users who work in Bank showed that $80 \%$ of workers suffered from at least 1 attack of a musculoskeletal disorder in the previous year, while $57 \%$ suffered from attacks during the previous week ${ }^{6}$. 
Poor postural habits and neck pain are increasingly common among individuals who work predominately on computer with poor postures including forward head position, protracted shoulder, and scapular winging and tipping where as keyboard and mouse were the main culprit referred for upper limb disorders ${ }^{7}$. A study was conducted by Punet L and Jensen C in the year of 1997 and 2002 showed in their result that the most complained problems are low back pain, neck pain and wrist pain. Foot and knee pain are the least complained pain when operating on computer systems. Pains are more severe in people with more than four years working experience on the computer system. Computer workers are at risk for the development of work related upper extremity musculoskeletal disorders $^{8,9}$. Job-related disability, a leading contributor to missed work, and the second most common neurological ailment- only headache is more common ${ }^{10}$. This study on musculoskeletal disorders among the computer users in our country would offer the best hope for identification of the problems, take necessary steps to minimize computer related disorders, reduce the cost and injuries associated with ergonomic hazards of computer usages. In consideration of the above facts, it is imperative to conduct such a study to focus the prevalence upon which appropriate measures for prevention of musculoskeletal disorders, promotion of health of the computer users and maintenance of the health of the individual. The study was conducted with the objectives to find out among bankers i) The prevalence of musculoskeletal disorder and ii) The association of musculoskeletal pain with computer use.

\section{MATERIALS AND METHODS}

A pretested, modified, questionnaire was distributed to the computer users who have complain of musculoskeletal pain working at three selected banks in Banani residential area of Dhaka city. A total of 400 respondents for the study were selected both male and female who used computer and having complain of musculoskeletal pain. All of the respondents gave their informed consent. Non randomized purposive sampling technique was applied here sample size was 400 , computer usages were at least 5 years and above. A three section questionnaire was employed as the survey instrument.

Section 1 sought information on demographic profile such as such as age, gender, marital status and education. Section 2 was on computer related factors and sought to elicit general information about risk factor s related to Computer used that may contribute to development of work-related musculoskeletal disorders (Desktop / Laptop /I Pad / I Phone) control, Duration of computer use (how many months/years, average day use) duration of computer use without interval in a day, Type of Chair used (Adjustable /Not adjustable), sitting arrangement (Comfortable/Not comfortable) Height of the monitor (Adjustable/Not adjustable) Height of the key board (Adjustable/Not adjustable) pain on stress (Yes/No). Section 3 contained items on musculoskeletal disorders related factors such as: type, duration, and severity of pain, part of the body affected by pain.
Data were summarized using the descriptive statistics of mean, standard deviation and percentages. Pearson's Chi-square analysis was used to determine the association of prevalence of selfreported musculoskeletal symptoms with personal characteristics and job risk factors. The data analyses were carried out using Statistical Package for Social Science (SPSS 16.0 version software Chicago). The significant level was set at 0.05 .

\section{RESULTS}

The table1 reveals that the mean age of the respondents were $33.58 \pm 12.326$ years. It is found from table 1 that $33.0 \%$, $30.8 \%, 20.0 \%, 10.5 \%, 5.7 \%$ of the respondents belonged to age group below 25years, 26-35 years, 36-45 years, 46-55 years, above 56 years respectively.

Table 1 : Distribution of respondents by socio demographic characteristic $(n=400)$.

\begin{tabular}{lcrr} 
Age group & Item & Frequency & Percent \\
& $<25$ & 132 & 33.0 \\
& $26-35$ & 123 & 30.8 \\
& $36-45$ & 80 & 20.0 \\
& $46-55$ & 42 & 10.5 \\
& $>56$ & 23 & 5.7 \\
& Total & 400 & 100 \\
Sex & Mean \pm SD & $33.58 \pm 12.326$ & \\
& Male & 277 & 69.2 \\
Educational status & Figher secondary & 123 & 30.8 \\
& Graduate & 400 & 100 \\
& Post graduate & 35 & 8.75 \\
& Total & 233 & 58.25 \\
& & 432 & 33 \\
& & 400 & 100 \\
\hline
\end{tabular}

Table also shows that among the respondents, $69.2 \%$ were male and $30.8 \%$ were female. It is found that $58.25 \%, 33.0 \%, 18.0 \%$ and $8.75 \%$ of the respondents belonged to the level of education had graduate, post graduate and higher secondary education respectively.

Table 2 : Distribution of respondents by computer related variables $(n=400)$.

\begin{tabular}{llcr}
$\begin{array}{l}\text { Type of Computer } \\
\text { (Multiple Responses) }\end{array}$ & Item & Frequency & Percent \\
& Desktop & 323 & 80.8 \\
& Laptop & 197 & 49.2 \\
& I-Pad & 20 & 5.0 \\
& I-Phone & 37 & 9.2 \\
Duration of & & & \\
Computer & & & \\
use in years & $5-13$ & 366 & 91.5 \\
& $14-23$ & 31 & 7.8 \\
& $>24$ & 3 & .8 \\
& Total & 400 & 100 \\
& MeanSD & & 8.423 .685 \\
\hline \hline
\end{tabular}


Table 2 founds that among the respondents, $80.8 \%$ were used desktop, 49.2\% laptop, 9.2\% I-Phone, and 5.0\% I-Pad. In this table shown that most of the respondents used desktop, second prefer laptop. Table also shows that the mean duration of computer used in $8.42 \pm 3.685$ years with a range from 5 years to 30 years. It is found from the table 2 that $91.5 \%, 7.8 \%$ and $0.8 \%$ of the respondents used computers from 5-13 years, $14-$ 23 years, 24 years and above respectively. Study found that $56.5 \%, 54.2 \%, 68.8 \%$, and $55.0 \%$ of the respondents used adjustable height of the chair, comfortable chair, adjustable height of monitor, adjustable height of keyboard of computer desk respectively. According to this result more than 50\% respondents used adjustable furniture, key board and monitor.

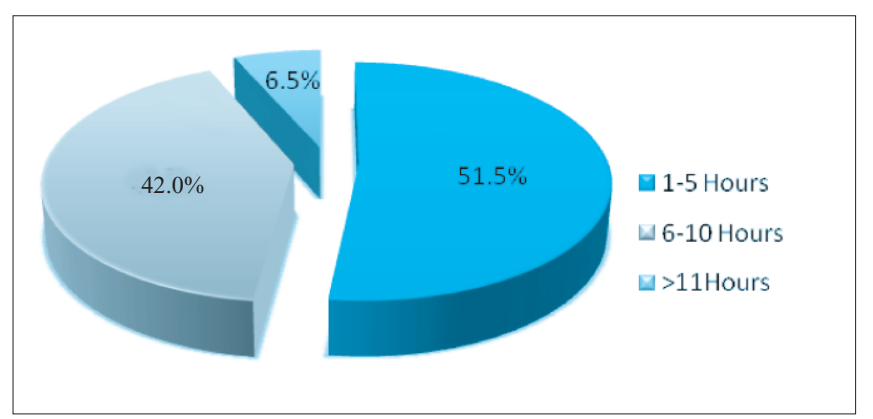

Figure 1 : Distribution of respondents by daily computer use.

Figure 1 revealed that $51.5 \%, 42.0 \%$ and $6.5 \%$ of the respondents belonged to use computers from 1-5 hours, 6-10 hours, 11 hours and above daily respectively.

Table 3 : Distribution of respondents by pattern of musculoskeletal disorders (Multiple responses).

\begin{tabular}{lrc} 
Area of pain & Frequency & Percentage \\
Neck & 301 & 75.2 \\
Upper back & 90 & 22.5 \\
Scapula & 45 & 11.2 \\
Shoulder & 123 & 30.8 \\
Elbow & 34 & 8.5 \\
Wrist & 76 & 19 \\
Fingers & 82 & 20.5 \\
Back & 192 & 48 \\
Knee & 43 & 10.8 \\
Leg & 24 & 6 \\
Ankle & 21 & 5.2 \\
Toe & 18 & 4.5 \\
\hline
\end{tabular}

Table 3 reveals that $75.2 \%, 48 \%, 30.8 \%, 22.5 \%, 20.5 \%, 19 \%$, $11.2 \%, 10.8 \%, 8.5 \%, 6 \%, 5.2 \%$ and $4.5 \%$ of the respondents complained the neck pain, back pain, shoulder pain, upper back pain, finger pain, wrist pain, scapula pain, knee pain, elbow pain, leg pain, ankle pain, toe pain respectively.
Table 4 : Distribution and association of respondents between age and severity of pain.

\begin{tabular}{|c|c|c|c|c|c|c|}
\hline \multirow{2}{*}{ Age in years } & \multicolumn{5}{|c|}{ Severity of pain } & \multirow[b]{2}{*}{ P-value } \\
\hline & Mild & oderate & Severe & Intolerable & Total & \\
\hline$>25$ & 49 & 59 & 15 & 9 & 132 & \\
\hline $26-35$ & 32 & 54 & 30 & 7 & 123 & \\
\hline $36-45$ & 18 & 32 & 25 & 5 & 80 & \\
\hline $46-55$ & 4 & 20 & 12 & 6 & 42 & 0.004 \\
\hline$<56$ & 2 & 13 & 5 & 3 & 23 & \\
\hline Total & 105 & 178 & 87 & 30 & 400 & \\
\hline
\end{tabular}

$\mathrm{p}$ value obtained from Pearson Chi-square $\left(\chi^{2}\right)$ test

It is found from the table no. 35 that p- value was 0.004 which was less than 0.05 that was statistically highly significant association between age and severity of pain.

Table 5 : Distribution and association of respondents between sex and severity of pain.

\begin{tabular}{lcccccc}
\multicolumn{2}{l}{ Sex Severity of pain } & & & & & \\
& Mild & Moderate & Severe & intolerable & Total & P-value \\
Male & 81 & 126 & 55 & 15 & 277 & \\
Female & 24 & 52 & 32 & 15 & 123 & .019 \\
Total & 105 & 178 & 87 & 30 & 400 & \\
\hline
\end{tabular}

$\mathrm{p}$ value obtained from Pearson Chi-square $\left(\chi^{2}\right)$ test

The table 5 shows that p-value was 0.019 which was less than 0.05 that was statistically significant association between sex and severity of pain.

Table 6 : Distribution and association of respondents between duration of computer use and severity of pain.

\begin{tabular}{lrrrrrr} 
Duration in & \multicolumn{6}{c}{ Severity of pain } \\
years & Mild & Moderate & Severe & Intolerable Total & P-value \\
\hline $5-13$ & 103 & 159 & 79 & 25 & 366 & \\
$14-23$ & 2 & 18 & 6 & 5 & 31 & \\
$>24$ & 0 & 1 & 2 & 0 & 3 & 0.019 \\
Total & 105 & 178 & 87 & 30 & 400 & \\
\hline
\end{tabular}

$\mathrm{p}$ value obtained from Pearson Chi-square $\left(\chi^{2}\right)$ test

It is shown from table 6 that $p$ - value was 0.019 which was less than 0.05 that was statistically significant association between duration of computer used in years and severity of pain.

\section{DISCUSSION}

When mostly affected area of pain asked to the respondents it was found that majority of them having pain in neck region of the body. These findings were similar to the finding of study carried out by the Estonia ${ }^{11}$. The study found most of the respondents belongs to graduate and post graduate education groups .These findings were similar to the finding of the study carried out by Malaysia and Delhi ${ }^{12,13}$. Majority of them used desktop and half of them were using laptop which is supported 
by a study conducted in Safe Computing Blog and Malaysia ${ }^{3,14}$. It was found from the present study that mean duration of computer use was $8.42+3.685$ years, average day use 5.72 +2.667 hours and used without interval $3.04+.921$ hour. It used from $1-5$ hours and $43 \%$ used without interval from 1 hour to 3 hours. These findings are similar to the finding of a study carried out in School of Physiotherapy, Dalhousie University of Canada ${ }^{15}$

There was a statistically significant association between duration of computer use in years and severity of pain and also we found the association between duration of computer use and problem persisting time in years here. These findings were supported by a study conducted in School of Physiotherapy, Dalhousie University of Canada and University of California $^{15,16}$.

The present Study revealed that half of the respondents $(56.5 \%)$ were using adjustable height of the chair of computer desk. Of them more than two third (68.8\%) used adjustable height of monitor while half of them $(55.0 \%)$ used adjustable height of keyboard. These findings were similar to the finding of study carried out by the study of Great Britain ${ }^{17}$.

According to the result $77.8 \%$ computer users complained pain when prolong computer used and $93.5 \%$ respondents said that problems persist from 1 year to 5 years of computer use. According to pain grading scale $44.5 \%$ complained moderate pain, $26.2 \%$ mild pain.
According to the measurement of pain grading scale most of the computer users suffering moderate pain and it was near about half of the respondents. These findings were similar to the finding of the study carried out by Finland ${ }^{18}$. No association found between Computer using without interval, average day use, adjustable chair, adjustable height of monitor, adjustable height of keyboard use and musculoskeletal pain .Similar findings are seen in a study conducted in Malaysia ${ }^{19}$.

\section{CONCLUSION}

A high proportion of Bangladeshi computer users among bankers reported musculoskeletal disorder at some body site in their occupational lives with the low back being injured most often. A mass awareness creation by Education program on prevention and coping strategies for musculoskeletal disorders within a widener ergonomic approach to promote the health of workers shoul ensure. Also, a comprehensive approach including system goals, task allocation, work organization and job design is needed. Further studies are required to elaborate the relation between job demands and loads as well as other organizational and social factors on occurrence of musculoskeletal disorder.

\section{DISCLOSURE}

All the authors declared no competing interest. 


\section{REFERENCES}

1. Tinubu. Work-Related Musculoskeletal Disorders among Nurses in Ibadan, South-west Nigeria: A cross-sectional survey. BMC Musculoskeletal Disorders. 2010;11:12.

2. Adedoyin RA, Idowu BO, Adagunodo RE,Idowu PA. Musculoskeletal Pain Associated With The Use Of Computer Systems In Nigeria.IJPSCPC. 2004; 3(2).

3. Safe Computer Tips.com, Stay Healthy and avoid injury while working long hours on your PC. http://www.safecomputingtips.com/musculoskeletal-disorder-keyboard.html). (Accessed on January 07, 2013 )

4. Johnson OE, Onigbinde AT, Onasanya SA, Emechete A Al, Gbela TO. An Assesment of Ergonomic Workstations and Pain Among computer users in a Nigerian University community. Nigerian Journal of Medical Rehabilitation (NJMR). 2008 ; 13(21).

5. Klalil TM, Abdel-Moty EM, Rosomoff RS, Rosomoff HL. Ergonomics in Back pain: A guide to prevention and rehabilitation. Netherlands: ISO Press Publihing London. 2003;10-12.

6. Akrouf QAS,Crawford JO, Al-Shatti AS, Kamel MI . Musculoskeletal disorders among bank office workers in Kuwait EMHJ .2010; 16 (1).

7. Green BN. A literature review of neck pain associated with computer use, Public health implications. Journal of the Canadian chiropractic association. 2008; 52(3): 161-167.

8. Punnett, L. Bergqvist U . Visual display unit work and upper extremity disorders. A review of epidemiological findings, National Institute for working Life. 1997; 1-161.

9. Jensen C, Finsen L, Sogaard K and Christensen H. Musculoskeletal symptoms and duration of computer and mouse use. IJIE. 2002;30:265-275.

10. Harris JS, Brigham CR. Lower back pain: Impact, causes, work relatedness, Diagnosis and therapy. 1990; 4(11): 84-86.

11. Oha K, Viljasoo V, Merisalu E. Prevalence of Musculoskeletal Disorders, Assessment of Parameters of Muscle Tone and Health Status among Office Workers Proceeding of the International Scientific Conference Biosystems Engineering. Tartu, Estonia. 2010;13.

12. Rajagopal V, Rosli RM, Rintai P, Rustim M, Benadus. Usai W. The Prevalence of Computer Related Musculoskeletal Pain among College Students: A Cross Sectional Study American Medical Journal. 2012; 3 (1): 33-36.

13. Sharma AK, Khera S, Khandekar J. Computer Related Health Problems among Information Technology Professionals in Delhi. Indian Journal of Community Medicine 2006; 31(1).

14. Venga SB, Morhan S. Common musculoskeletal disorders among computer users and modification of work layout. 2013; 01:15-19.

15. McLean L, Tingley M, Scott RN and Rickards J. Computer terminal work and the benefit of micro breaks. Applied Ergonomics. 2001; 32:225-237.

16. Schlossberg EB, Morrow S, Llosa AE, Mamary E, Dietrich P, Rempel DM. Upper extremity pain and computer use among engineering graduate students. 2004 ; 46(3):297-303.

17. Hasleman Bl. Hunter's Disease or occupations: Repeated movements and repeated trauma. Boston In: Raffle PAB, Asams PH, Baxter PJ, Lee WR and Edward Arnold Publishers. 1992;8:515-527.

18. Hakala. Musculoskeletal symptoms and computer use among Finnish adolescents pain intensity and inconvenience to everyday life: A cross sectional study. BMC Musculoskeletal Disorders. 2012; 13(41):1186-1471.

19. Rajagopal V, Rosli RM, Rintai P, Rustim N, Benadus R, Usai W. The Prevalence of Computer Related Musculoskeletal Pain Among College Students : A Cross Sectional Study. 2012; 3 (1): 33-36. 